\title{
The Impact of an Educational Program on Blood and Blood Products Transfusion on Nurses' Level of Knowledge and Performance
}

\author{
Mohammad Islami Vaghar \\ Department of midwifery, Tehran Medical sciences branch, Islamic Azad university, Tehran, Iran \\ Corresponding Author: E-mail: drislamivaghar@yahoo.com \\ Received: April 13th, 2018 - Accepted: August 22nd, 2018
}

\begin{abstract}
Objective and background: This study aimed to evaluate the impact of an educational program on blood and blood products transfusion on nurses' knowledge and performance in hospitals affiliated with Mashhad University of Medical Sciences.

Method: The present study was a semi-experimental before-after study. We selected study participants through the simple random sampling method using sampling framework of all reference population. Data collection tool was a valid and reliable questionnaire. In order to evaluate the effect of the educational program on nurses' level of knowledge and practice, we asked them to fill out the questionnaires before and after the education course. We analyzed data using SPSS 22. Descriptive statistics such as frequency and percentages and analytical statistics such as Mann- Whitney, Wilcoxon and Kruskal-Wallis were used to report the results. The significance level of the $p$-value was assumed to be $<0.05$.

Results: Our analysis revealed a significant difference in the mean score of the nurses' level of knowledge before and after the education ( $p=0.001)$. There was also a significant difference in the mean score of veteran nurses' performance before and after the intervention $(p<0.05)$. The association between sex and mean score of nurses' performance was not significant before and after the intervention. The association between nurses' knowledge score and age, sex, work experience and department of the hospital was not significant $(p>0.05)$.

Conclusion: Educational programs about blood transfusion can positively influence nurses' knowledge and performance. There is a need to improve nurses' knowledge and performance about the inadvertent side effects of blood transfusion.
\end{abstract}

Keywords: Knowledge and Performance, Education, Transfusion, Nurses

\section{Introduction}

Millions of patients need blood and blood products transfusions all around the world [1]. Blood transfusion is defined as the process by which the blood of one person is injected into another one's circulation for medical purposes. In the early twenty century, blood transfusion contributed to various adverse side effects; however, nowadays these effects are preventable through educating medical care providers and screening blood and blood products [2]. Blood transfusion is a vital need for some patients, but without caution, it can be a life-threatening intervention $[3,4]$. It is estimated that in every 13000 cases of blood transfusion one error occurs mostly due to human errors which are preventable through appropriate education and reform in blood transfusion protocols [5, 6]. Regarding the important role of nurses in a safe and effective blood transfusion, it is necessary to improve their knowledge and skills [1]. Blood transfusion is a complex procedure including five stages and nurses are involved in four of them including preparing blood units, collecting blood packs, activities related to before and after transfusion and patient safety monitoring $[7,8]$. Blood transfusion is an important medical intervention which requires sufficient knowledge and skills [2]. Many studies have been conducted on the level of knowledge and awareness of nurses and physicians about blood transfusion $[1,3,7]$. However, regarding the increasing demand for blood transfusion in hospitals and its role in saving patients' lives, it seems necessary to improve nurses' level of knowledge and performance to ensure the safety of this intervention. This study aimed to evaluate the impact of educational programs on blood and blood products transfusion on nurses' level of knowledge and skills in hospitals affiliated with Mashhad University of Medical Sciences.

\section{Methods}

We conducted a semi-experimental before-after study on nurses in hospitals affiliated with Mashhad University of Medical Sciences in 1396. The sample size was estimated to be 25 participants based on previous studies [9], using: $\frac{(u+v)^{2}\left(S_{1}^{2}+S_{2}^{2}\right)}{\left(m_{1}-m_{2}\right)}$ Formula, significance level of 0.05 and the power of study equal to 0.9 . We included 50 participants 
to improve the power of the study. We used the simple random sampling method to collect study participants. Each nurse in different departments of the hospital had the same probability to be included in the study. Inclusion criteria were: having at least a B.Sc. degree, at least two years of working experience in hospital departments related to blood and blood products transfusion and not having attended any educational courses about transfusion before. Exclusion criteria were: not attending the course due to illness, traveling or being reluctant to participate in the study, being absent for more than one session. Data collection tool was a questionnaire designed by Pourfarzad and et al. which was validated under the supervision of prominent professors in this field [10] This questionnaire had three parts: the first part consisted of demographic information (age, sex, level of education, marital status, working experience, hospital department). The second part included 14 questions regarding the knowledge area such as the allowed interval of injecting one unit of blood, the allowed interval between taking out blood packs from the blood bank until the injection, the allowed serums that can be prescribed at the same time with the blood serum, the names of coagulation factors, the adverse side effects of blood transfusion, the appropriate reactions to hemolytic complications, the rational use of platelet transfusion, hemoglobin response to 1 unit of packed red blood cells, the blood warming method, the differences in fresh vs. old blood, the method of keeping fresh frozen plasma (FFP) and drugs for anemia. Each question had four answers, one was true and three were false. We assigned 1 point for a true answer and 0 points for a false one. The lowest and highest scores were 0 and 14 , respectively. The levels of knowledge were defined as poor (0-7), intermediate: (8-10) and good (11-14). The third part of the questionnaire was related to the blood transfusion performance that we evaluated using the Likert scoring system with values of 0 (never) and 4 (always). The lowest score was 0 and the highest one was 40 . The levels of performance were defined as low (0-30), intermediate (3136) and good (37-40). The researcher held the educational course through the question-and-answer method and by delivering a presentation in 6 sessions to improve nurses' knowledge and performance. The nurses were classified into three groups, two groups of 20 and a group of 15 individuals. In order to examine the association between the intervention and the nurses' level of knowledge and performance, before and after the course we asked them to fill out the questionnaires. We analyzed data using SPSS 22, descriptive statistics such as frequency and percentage and analytical statistics such as Mann- Whitney, Wilcoxon, and Kruskal-Wallis. Results were considered significant if $p<0.05$.

\section{Results}

Results showed that before the intervention the level of knowledge and performance for the majority of participants was poor $(54 \%)$ and intermediate $(64 \%)$, respectively. However, after the intervention, the level of knowledge and performance of the majority of participants reached the good level ( $72 \%$ and $88 \%$, respectively). (Table 1)

Results indicated a significant difference between mean scores of knowledge and performance before and after the intervention $(p=0.001)$. (Table 2)

The results showed that $54 \%$ of participants were women, $62 \%$ of nurses were younger than 30 years of age. $26 \%$ of nurses were working in the emergency department, $18 \%$ in gynecology and $16 \%$ in internal medicine and general surgery. After the intervention, the mean performance score of veteran nurses increased significantly $(p<0.05)$. Before the intervention, we observed a significant association between mean score of performance, age and department. However, after the intervention, this association was not significant anymore $(p>0.05)$. Sex was not significantly associated with nurses' performance neither before nor after the intervention. Also, the association between nurses' mean knowledge score and age, sex, work experience and department was not significant $(p>0.05)$. (Table 3)

\section{Discussion}

The present study aimed to evaluate the impact of an educational intervention on nurses' level of knowledge and

Table 1: Nurses' level of knowledge and performance about blood and blood transfusion before and after the educational intervention

\begin{tabular}{lllc} 
Variable & & Level & Frequency (\%) \\
Before & Knowledge & Poor & $27(54)$ \\
intervention & & Intermediate & $16(32)$ \\
& & Good & $7(14)$ \\
& \multirow{2}{*}{ Performance } & Poor & $5(10)$ \\
& & Intermediate & $32(64)$ \\
After & Knowledge & Poor & $13(26)$ \\
intervention & & Intermediate & $1(2)$ \\
& & Good & $36(72)$ \\
& & Poor & $0(0)$ \\
& & Performance & $6(12)$ \\
Total & & Intermediate & $44(88)$
\end{tabular}


Table 2: Comparison between nurses' level of knowledge and performance about blood and blood transfusion before and after the educational intervention

$\begin{array}{llcccc}\text { Variable } & & \text { Mean } \pm \text { SD } & \text { Min } & \text { max } & \text { P-value } \\ \text { Knowledge score } & \text { Before intervention } & 7.66 \pm 2.18 & 4 & 12 & 0.001 \\ & \text { After intervention } & 11.56 \pm 1.84 & 7 & 14 & \\ \text { Performance score } & \text { Before intervention } & 34.92 \pm 2.94 & 26 & 40 & 0.001 \\ & \text { After intervention } & 38.38 \pm 1.48 & 34 & 40 & \end{array}$

Table 3: The association between socio-professional characteristics and knowledge and performance scores

\begin{tabular}{|c|c|c|c|c|}
\hline variable & & Frequency (\%) & Knowledge score (p-value) & Performance score ( $p$-value) \\
\hline \multirow[t]{2}{*}{ Sex } & Female & $27(54)$ & $0.60^{*}$ & $0.17^{*}$ \\
\hline & Male & $23(46)$ & $0.44^{* *}$ & $0.10^{\star *}$ \\
\hline \multirow[t]{2}{*}{ Age (years) } & $<30$ & $31(62)$ & $0.70^{*}$ & $0.002^{*}$ \\
\hline & $30<$ & $19(38)$ & $0.99^{* *}$ & $0.70^{* *}$ \\
\hline \multirow[t]{2}{*}{ Working experience (years) } & $<6$ & $33(66)$ & $0.14^{*}$ & $0.001^{*}$ \\
\hline & $6<$ & $17(34)$ & $0.39^{* *}$ & $0.014^{* *}$ \\
\hline \multirow[t]{9}{*}{ Department } & Emergency & $13(26)$ & & \\
\hline & & & $\begin{array}{l}0.44^{*} \\
0.41^{* *}\end{array}$ & $\begin{array}{l}0.013^{*} \\
0.42^{* *}\end{array}$ \\
\hline & Internal medicine & $8(16)$ & & \\
\hline & Dialysis & $4(8)$ & & \\
\hline & Gynecology & $9(18)$ & & \\
\hline & Neonates & $4(8)$ & & \\
\hline & General surgery & $8(16)$ & & \\
\hline & Operation room & $2(4)$ & & \\
\hline & Pediatrics & $2(4)$ & & \\
\hline
\end{tabular}

* Before intervention

${ }^{* *}$ After intervention

performance. According to the results, $54 \%$ of participants were women and all had a B.Sc. degree. In a study conducted by Silva and et al., more than $2 / 3$ of participants were women with a B.Sc. degree [11]. In our study, before the educational intervention, most of the nurses had insufficient knowledge and intermediate performance. However, this intervention increased their knowledge and performance to a satisfactory level. In a Turkish study, the majority of nurses had intermediate performance and their knowledge scores were 50-100 [12] while a French study reported that nurses' level of knowledge and performance about transfusion was poor. The nurses had knowledge about patients and appropriate blood products in $54 \%$ of cases. [13]. A study in Iran revealed that in medical care providers the level of knowledge about blood transfusion was poor in $26.2 \%$ of cases, intermediate in $22.1 \%$ and satisfactory in $51.6 \%$. This study emphasized the importance of developing a guideline to improve personnel' level of knowledge [14]. Findings of the present study showed a significant difference between knowledge and performance scores before and after the intervention. This finding was in agreement with other studies [15, 2]. Previous studies revealed that the effect of education on nurses' performance was associated with other factors such as the method of education and their motivation to improve themselves [16, 17]. Regarding the important role of nurses in transfusion safety, it seems necessary to develop an appropriate educational program to improve their level of knowledge and performance [10, 14]. Similar to the results of other studies, our findings indicated a significant difference in the level of knowledge and performance in veteran nurses before and after the intervention $[15,18]$. On the one hand, older nurses are more experienced in their jobs, but on the other hand, they had attended more educational courses about transfusion.

The results of the present study revealed that before the intervention, there was a significant association between age, department and nurses' performance score. Nevertheless, after the intervention, this difference was not significant. Sex was not significantly associated with 
the performance score before and after the intervention. Studies by Watson et al. and Abdullahi and et al., showed no significant association between performance and sex, marital status, participation in educational courses and working experience $[19,20]$. Blood transfusion is a lifesaving medical intervention, but it may become life-threatening if simplistically considered a basic medical procedure. In the medical care system, we aim to improve the effectiveness of blood transfusion. In concordance with other studies, our findings indicated that before and after the intervention, the association between nurses' performance score and sex, age, working experience, department of occupation was not significant [21-26]. Lee and et al. reported a significant association between nurses' performance score and their demographic characteristics (age, work experience and so forth) [26]. In several studies, it was indicated that nurses who attended educational courses were more knowledgeable about blood transfusion [13, 24, 25]. Regarding the important role of nurses in handling patients, it seems necessary to develop educational programs to improve their level of knowledge and practice.

\section{Conclusion}

Educational programs regarding blood transfusion can positively impact on nurses' level of knowledge and performance. All of the medical care personnel must be well educated about the appropriate condition of blood storage, injection and reaction to side effects of blood or blood products transfusion. It seems necessary to develop standard guidelines and educational courses about transfusion for nurses to improve their level of knowledge and practice.

\section{Conflict of Interest}

The authors confirm that there are no conflicts of interest.

\section{References}

1. Hijji B, Parahoo K, Hussein MM, Barr O. Knowledge of blood transfusion among nurses. Journal of clinical nursing. 2013;22(1718):2536-50.

2. Reza PA, Aziz SV, Ali MA, Marjan MH, Reza TM. Evaluation of knowledge of healthcare workers in hospitals of Zabol city on proper methods of blood and components transfusion. Asian journal of transfusion science. 2009;3(2):78-81.

3. Aslani Y, Etemadyfar S, Noryan K. Nurses' knowledge of blood transfusion in medical training centers of Shahrekord University of Medical Science in 2004. Iranian journal of nursing and midwifery research. 2010;15(3):141.
4. Kanemitsu Y. 24-hour system of the blood transfusion services at the university hospital. Rinsho byori The Japanese journal of clinical pathology. 2003;51(1):57-62.

5. Bolton-Maggs PH. Transfusion safety in 2012: main messages from the SHOT Annual Report for 2012. Transfusion medicine (Oxford, England). 2013;23(4):217-8.

6. Holmberg JA. Blood you can trust: global trends in transfusion safety. MLO: medical laboratory observer. 2015;47(10):20, 2.

7. Hiji BM, Oweis AE, Dabbour RS. Measuring knowledge of blood transfusion: A survey of Jordanian nurses. Am Int J Contemp Res. 2012;2:77-94.

8. Lamanna C, Baroni M, Bisin S, Gianassi S, Bambi F, Caselli D, et al. Key role of staff competencies for patient and donor safety in a bone marrow transplantation unit: design and implementation of an accredited training and self-assessment program. Transplantation proceedings. 2010;42(6):2254-6.

9. Kasraian $L$. The awareness of medical staff of hospitals in Shiraz about transfusion medicine and the impact of education. Scientific Journal of Iranian Blood Transfusion Organization. 2014;11(3).

10. Purfarzad Z, Farmahini Farahani M, Ghamarizare Z, Ghorbani M, Zamani M. Nurses' Knowledge and practice of blood transfusion in hospitals of Arak in 2010. Scientific Journal of Iranian Blood Transfusion Organization. 2012;9(3):337-45.

11. da Sila KFN, Floriano DR, Duarte RD, Tavares JL, dos Santos Félix MM, Silva QCG, et al. Blood Transfusion in Cancer Patients: Knowledge of the Nursing Team. International Archives of Medicine. 2016;9.

12. Bayraktar N, Erdil F. Blood transfusion knowledge and practice among nurses in Turkey. Journal of intravenous nursing: the official publication of the Intravenous Nurses Society. 2000;23(5):310-7.

13. Saillour-Glenisson F, Tricaud S, Mathoulin-Pelissier S, Bouchon B, Galperine I, Fialon P, et al. Factors associated with nurses' poor knowledge and practice of transfusion safety procedures in Aquitaine, France. International journal for quality in health care: journal of the International Society for Quality in Health Care. 2002;14(1):25-32.

14. Reza PA, Aziz SV, Ali MA, Marjan MH, Reza TM. Evaluation of knowledge of healthcare workers in hospitals of Zabol city on proper methods of blood and components transfusion. Asian journal of transfusion science. 2009;3(2):78.

15. Aghajani M, Ajorpaz NM, Mohammadi S, Mohammadi A. Designing Multi-media learning software (MLS): Effects on surgical technology students' knowledge, attitude and practice. Life Science Journal. 2013;10(SPL. IS):7-11.

16. Rolfe G. Beyond expertise: theory, practice and the reflexive practitioner. Journal of Clinical Nursing. 1997;6(2):93-7.

17. McCaugherty $D$. The theory-practice gap in nurse education: its causes and possible solutions. Findings from an action research study. Journal of advanced nursing. 1991;16(9):1055-61.

18. Rafii F, Jan Amiri M, Dehnad A, Haghani H. The Effect of Workshop and Multimedia Training Methods on Nurses' Knowledge and Performance on Blood Transfusion. Journal of Client-Centered Nursing Care. 2016;2(4):223-30.

19. Watson D, Hearnshaw K. Understanding blood groups and transfusion in nursing practice. Nursing Standard. 2010;24(30):41-8.

20. AA. Abdollahi, H. Rahmani, B. Khodabakhshi, N. Behnampour Assessment of level of knowledge, attitude and practice of employed nurses to nosocomial infection in teaching hospitals of Golestan University of Medical Sciences (2000). Journal of Gorgan University of Medical Sciences. 2003;5(1):80-6.

21. Harrison LL, Novak D. Evaluation of a gerontological nursing continuing education programme: effect on nurses' knowledge and 
attitudes and on patients' perceptions and satisfaction. Journal of advanced nursing. 1988;13(6):684-92.

22. Stein LS. The effectiveness of continuing medical education: eight research reports. Academic Medicine. 1981;56(2):103-10.

23. Silva MAd, Torres GdV, Melo GdSM, Costa IKF, Tiburcio MP, Farias TYA. Conhecimento acerca do processo transfusional da equipe de enfermagem da uti de um hospital universitário. Ciênc cuid saúde. 2009;8(4):571-8.

24. Dubey A, Sonker A, Chaudhary RK. Evaluation of health care workers' knowledge and functioning of blood centres in north India: a questionnaire based survey. Transfusion and apheresis science: official journal of the World Apheresis Association: official journal of the European Society for Haemapheresis. 2013; 49(3):565-70.

25. Tavares JL, Barichello E, De Mattia AL, Barbosa MH. Factors associated with knowledge of the nursing staff at a teaching hospital on blood transfusion. Revista latino-americana de enfermagem. 2015;23(4):595-602.

26. Azdiana TDS, Arzuar ARN, Siew Lee LE. Knowledge of Blood Transfusion among Nurses at Hospital Pulau Pinang: Nursing Responsibilities and Patient Management Related to Transfusion Reactions. Education in Medicine Journal. 2016;8(4). 